\title{
Parâmetros de controle \\ de concreto projetado para \\ revestimento primário de túneis
}

\author{
LÍVIA NEVES CUNHA MARTINS - ENGENHEIRA CIVIL \\ Consultora na ÁREA DE GEStÃo da Qualidade, COM ÊNFASE EM \\ Controle Tecnológico de Concreto em obras de infraestrutura \\ de grande porte. Mestranda do Programa de Mestrado \\ Profissional em HabitaÇão do IPT
}

\author{
PAULO HELENE \\ Professor Titular da USP — Diretor da PhD Engenharia
}

\section{RESUMO}

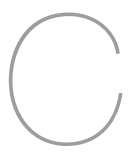

om base em 1.700 ensaios e na análise de $20.000 \mathrm{~m}^{3}$ de concreto projetado para revestimento primário de $1.500 \mathrm{~m}$ de túneis, foi avaliada a faixa percentual mais adequada de aditivo acelerador de pega no concreto, com vistas ao seu melhor desempenho em termos de abatimento, resistência à compressão no concreto jovem até 120 minutos e resistência até 28 dias no concreto extraído de placas de controle.

\section{INTRODUÇÃO}

Este artigo técnico tem como finalidade a análise de resultados de resistência do concreto projetado ao longo do tempo, correlacionando-a a variáveis que possam interferir no desempenho e qualidade final do concreto projetado para revestimento primário de túneis.

A especificação europeia (EFNARC, 1996) define o concreto projetado como uma mistura de cimento, adições, agregado, aditivo e água, projetada úmida e pneumaticamente a partir de um bico projetor no próprio local para produzir uma massa homogênea e densa. O concreto projetado pode, também, incluir aditivos especiais, fibras ou uma combinação destes.
O uso de concreto projetado, via seca, para suporte de túneis em NATM (Novo Método Austríaco de Execução de Túneis) foi introduzido no Brasil, na década de 1970, durante as obras da Rodovia Imigrantes (SILVA, 1997). Na década de 1990, a EPUSP, com patrocínio da CBPO, desenvolveu e introduziu o concreto projetado via úmida, com e sem fibras, pela primeira vez, no Brasil, em túneis NATM do Metrô de São Paulo (ARMELIN, 1992; PRUDÊNCIO Jr., 1993; PALERMO, 1997; FIGUEIREDO, 1997).

Atualmente, com o desenvolvimento da engenharia global de túneis, aliado a projetos que requerem cada vez mais celeridade, o procedimento de revestimento de túneis com concreto projetado, via úmida, tem sido amplamente aplicado como o principal método de suporte.

Uma das características mais importantes do concreto projetado, especificamente quando aplicado em túneis, é o desenvolvimento precoce de resistência mecânica muito elevada, obtida, na maioria dos casos, por meio de um aditivo acelerador, que, durante o processo de projeção, permite que o concreto seja aderido à superfície e endurecido em minutos.
O processo de concreto projetado pode ser dividido em dois tipos: úmido e seco. No processo de mistura a seco, a água é adicionada no bocal do injetor de distribuição a uma mistura seca, o que acarreta maior variabilidade. No processo úmido, os componentes do concreto projetado e a água são misturados (geralmente no próprio caminhão betoneira) antes do início do descarregamento em um equipamento de deslocamento positivo (bomba de concreto), que então fornece a mistura hidráulica e homogênea para o difusor, onde o ar é adicionado para projetar o material na superfície do maciço.

Nos dias atuais, o processo de mistura úmida é preponderantemente utilizado com frequência na construção de túneis devido ao rendimento mais elevado e à menor produção de poeiras, diminuindo o risco de doenças ocupacionais, em comparação com o processo de mistura seca. Além disso, pode-se citar vantagens como fácil obtenção da espessura projetada, baixa reflexão, melhor desempenho mecânico e menor variabilidade da resistência mecânica, que the conferem ampla aplicação como suporte permanente ou temporário. 


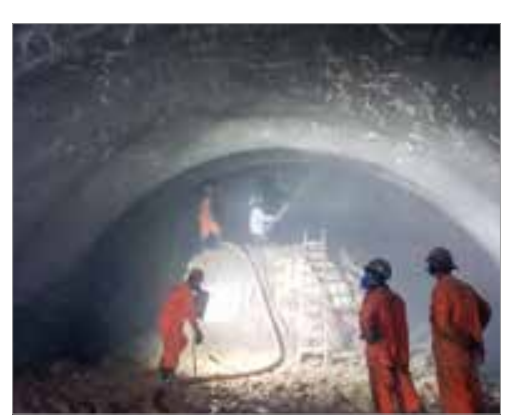

Fonte: Autores, 2020

Figura 1

Exemplo de concreto sendo projetado, via úmida, para revestimento primário de túnel escavado pelo sistema NATM

O concreto projetado (vide Fig.1), na sua composição básica, não difere muito do concreto convencional. Assim como ocorre com o concreto convencional, as propriedades do concreto projetado dependem da relação água e cimento, da qualidade dos agregados, dos tipos de aditivos utilizados, bem como do tipo de cimento e das práticas construtivas empregadas.

\section{EXPERIMENTO}

A autora acompanhou o lançamento de $20.000 \mathrm{~m}^{3}$ de concreto projetado, utilizado para revestimento primário de túnel escavado pelo sistema NATM, e coletou dados de controle desse concreto, em uma extensão de aproximadamente 1.500 m de túneis.

Os resultados da pesquisa são provenientes da análise de mais de 1.500 resultados de ensaios de testemunhos e corpos de prova do concreto entregue por cerca de 3.900 caminhões betoneira fornecidos à obra, durante um período de 20 meses.

\section{I Variáveis dependentes}

As variáveis dependentes são os fatores resultantes e de maior interesse neste experimento real e prático, reflexos da interação com as variáveis independentes e intervenientes.

Adotou-se, como variáveis dependentes de interesse, a consistência do concreto fresco, medida pelo abatimento (slump) em mm, conforme método ABNT NBR NM 67. No concreto jovem, recém-projetado, a resistência foi verificada pelo Penetrômetro de Profundidade Constante (PPC) medida pela Agulha de Meynadier, conforme Método A da EN 14488-2. No concreto endurecido, a resistência à compressão foi obtida pelo rompimento de corpos de prova extraídos (testemunhos) das placas moldadas para controle, conforme métodos ABNT NBR 5739 e NBR 7680-1.

\section{Z.I.I CONSISTÊNCIA MEDIDA PELO ABATIMENTO DO TRONCO DE CONE (SLUMP)}

O recebimento do concreto é parte fundamental no sucesso da aplicação. É no recebimento que é feita a conferência da consistência (slump) inicial (vide Fig. 2). A especificação do seu valor é determinada no estudo experimental de dosagem, ou seja, é resultado da interação da composição dos componentes do concreto. Assim, qualquer alteração no traço de concreto pode afetar a consistência (slump) inicial.

Após a conferência dessa consistência (slump) inicial, e estando em conformidade com o especificado, o aditivo superplastificante é acrescentado no canteiro de obra. Esse aditivo é responsável por fluidificar a mistura, aumentando o slump, conferindo maior trabalhabilidade para a finalidade e possibilitando o transporte do concreto através da rede de tubulação, da bomba e do mangote (vide Fig. 3). Neste estudo, foi especificado um abatimento inicial de $(40 \pm 10) \mathrm{mm}$ e um valor final, após colocação do aditivo superplastificante, de $(180 \pm 30) \mathrm{mm}$

O concreto bem homogeneizado evita redosagens de aditivo que, em excesso, pode levar à segregação, excesso de rebote ou reflexão e comprometimento do desempenho final. Slump final muito baixo, ou seja, consistência seca ou plástica ao invés de fluída, pode entupir a tubulação, além de causar uma taxa de reflexão maior.

\section{I.2 RESISTÊNCIA DO CONCRETO JOVEM (Agulha de Meynadier)}

Para continuidade e produtividade do avanço de escavação do túnel, é necessário que o concreto atinja certas resistências especificadas a idades prematuras. A Fig. 4 mostra um gráfico típico das curvas de resistência do concreto jovem.

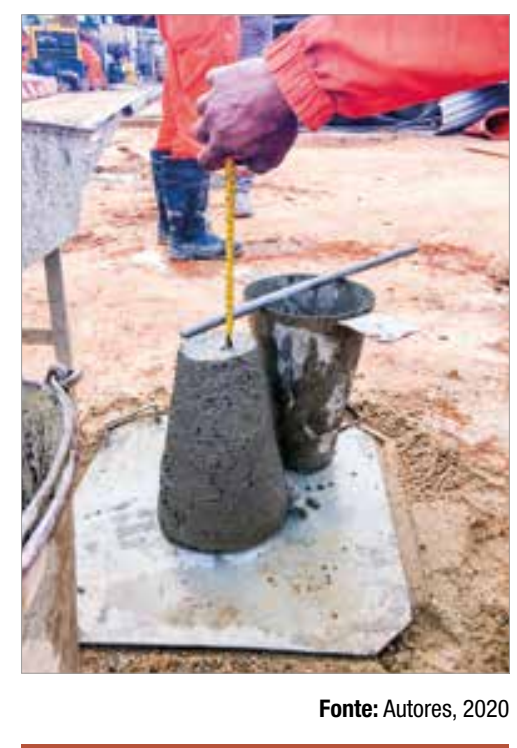

Figura 2

Conferindo a consistência inicial (slump) do concreto fresco recebido na obra 
O ensaio através do penetrômetro de profundidade constante (PPC ou Agulha de Meynadier) possibilita a obtenção de resistências

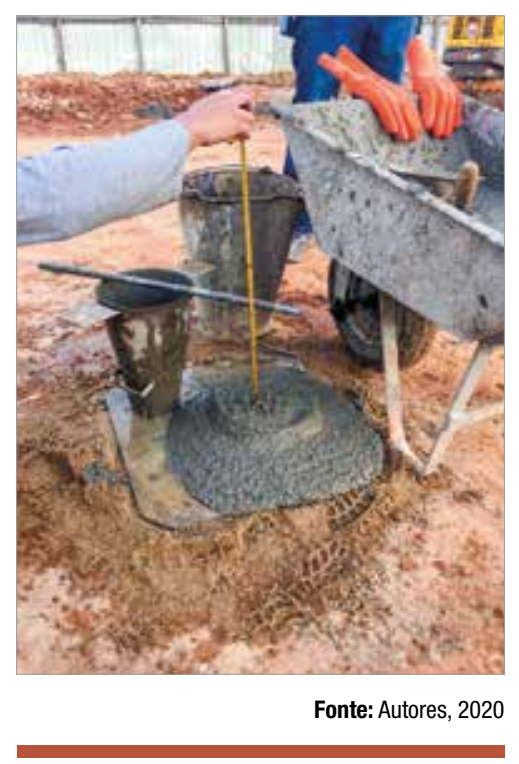

Figura 3

Conferindo a consistência final (slump) do concreto fresco recebido na obra, após inserção de aditivo superplastificante, sem alteração da relação a/c compreendidas entre 0,2 MPa e 1,2 MPa.

Segundo o gráfico da Fig. 4, especificado em muitos documentos de túnel com sistema de escavação tipo NATM, a resistência do concreto projetado, na parede do túnel, deve seguir um crescimento mínimo de referência indicado por curvas J1/A, J2/B ou J3/C.

Como se nota, são três classes de concreto, cada uma com sua curva independente de crescimento de resistência à compressão. No caso específico deste controle e estudo prático e experimental, o projetista estrutural não especificou a que curva o concreto deveria obedecer em cada trecho do túnel.

\section{I.3 RESISTÊNCIA DO CONCRETO ENDURECIDO}

Os valores de resistência à compressão foram obtidos de testemunhos extraídos de placas de controle, e ensaiados à compressão simples em diferentes idades.

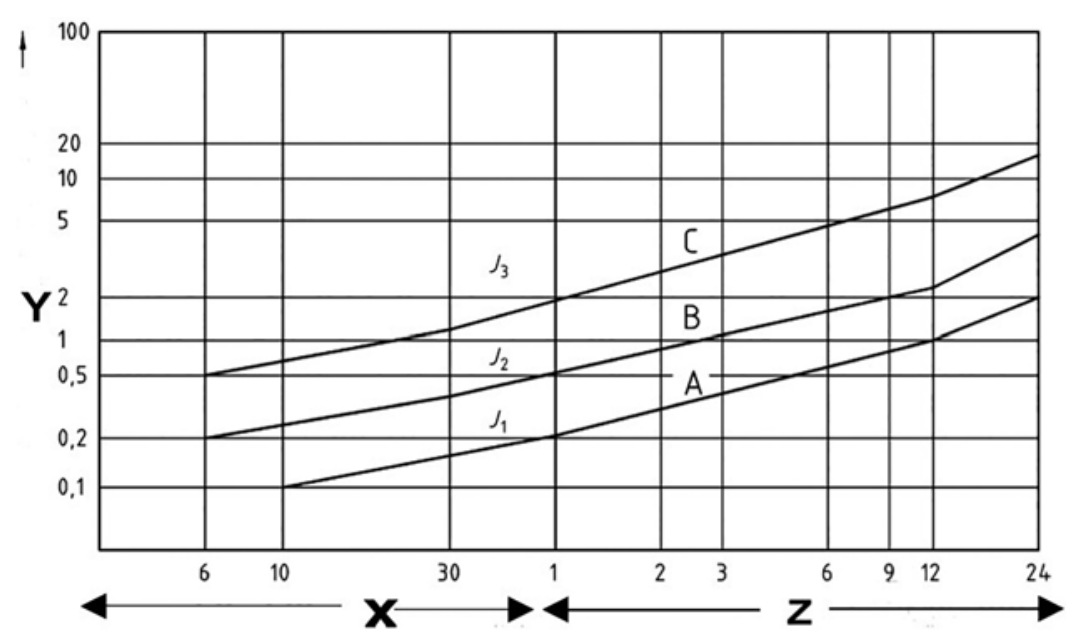

Legenda: Y: Resistência à compressão $\mathrm{f}_{\mathrm{c}}$ em MPa; X: Minutos; Z: Horas

Fonte: Autores, 2020

\section{Figura 4}

Exemplo típico de gráfico bi logarítmico de evolução da resistência à compressão $(\mathrm{Y})$ do concreto, em MPa, em função da idade do concreto jovem em minutos e horas
Neste estudo, as resistências especificadas em projeto estrutural foram as apresentadas na Tabela 1.

\subsection{Variáveis independentes}

Variáveis independentes são aquelas inalteradas durante o experimento.

No trabalho em questão, tem-se:

Mesmos materiais (insumos);

- Mesmo traço do concreto projetado;

Mesma central de concreto (empresa de serviços de concretagem);

- Mesmos equipamentos de projeção via úmida (uma bomba a rotor e outra a pistão);

- Mesmos operadores dos equipamentos de projeção e mangote.

\section{Z.I TRAÇO DO CONCRETO}

Desde o início das escavações do túnel, a obtenção das resistências especificadas sempre foi um desafio. Por conseguinte, vários fatores foram investigados, a fim de se esclarecer possíveis causas e estabelecer soluções exequíveis no âmbito operacional e econômico.

O traço desenvolvido experimentalmente no laboratório visou atender às

Tabela 1 - Parâmetro da resistência do concreto projetado em função de sua idade, especificado no projeto estrutural da obra

Parâmetros de controle da resistência do concreto projetado

$\begin{array}{cc}12 \mathrm{~h} & >10 \mathrm{MPa} \\ 24 \mathrm{~h} & >15 \mathrm{MPa} \\ 48 \mathrm{~h} & >20 \mathrm{MPa} \\ 28 \text { dias } & >25 \mathrm{MPa}\end{array}$

Fonte: Autores, 2020 
Tabela 2 - Especificações utilizadas para estudo experimental de dosagem do concreto projetado, referido ao concreto final na parede, aferido por corpos de prova extraídos de placas de controle

\begin{tabular}{|c|c|c|c|}
\hline \multicolumn{4}{|c|}{ Especificação da dosagem } \\
\hline (28 dias) $f_{c k}$ & $=$ & 25,0 & $\mathrm{MPa}$ \\
\hline$(28$ dias $) f_{c j}$ & $=$ & 30,0 & $\mathrm{MPa}$ \\
\hline Abatimento inicial & $=$ & $40 \pm 10$ & $\mathrm{~mm}$ \\
\hline Abatimento final & $=$ & $180 \pm 30$ & $\mathrm{~mm}$ \\
\hline (28 dias) desvio padrão $\mathrm{s}_{d}$ & $=$ & 3,0 & $\mathrm{MPa}$ \\
\hline Agregado graúdo & $=$ & Brita 0 & - \\
\hline Tipo de lançamento & $=$ & Projetado via úmida & - \\
\hline Relação a/c & $\leq$ & 0,42 & $\mathrm{~kg} / \mathrm{kg}$ \\
\hline Consumo de cimento & $\geq$ & 400 & $\mathrm{~kg} / \mathrm{m}^{3}$ \\
\hline
\end{tabular}

especificações de dosagem descritas na Tabela 2. Observar que estas especificações visam ao concreto final, na parede do túnel, controlado através de testemunhos de concreto extraídos de placas de controle. No estudo de dosagem, há necessidade de dar vários passos: obter um traço inicial com consistência seca; adicionar aditivo superplastificante e obter um concreto fluido, e, finalmente fazer um protótipo ou trecho do túnel, no qual deve ser adicionado também o aditivo acelerador no bico do mangote.

Os resultados obtidos do estudo de dosagem, realizado pelo método IBRACON, a partir dessa especificação, estão apresentados nas Tabelas 3 e 4.

Os resultados apresentados na Tabela 4 respondem às exigências e limites de traço e composição dos concretos especificados no projeto estrutural, sendo a resistência à compressão obtida, um valor potencial decorrente, mas não limitante. Na prática, esse valor potencial é bastante reduzido como consequência do processo de transporte e lançamento. Os aditivos aceleradores adicionados no momento da projeção reduzem significativamente esses valores potenciais, que só são possíveis de serem obtidos no laboratório, conforme demonstrado na Tabela 5.

Após obtenção dos resultados encontrados no concreto ensaiado em laboratório, o traço é verificado em campo, reproduzido sob as mesmas condições habituais de aplicação, ou seja, através dos mesmos equipamen-
Fonte: Autores, 2020 o uso de aditivo acelerador de pega

Fonte: Autores, 2020
Tabela 3 - Resultados do estudo de dosagem do concreto projetado, referido ao concreto de consistência seca (inicial) e ao concreto com aditivo superplastificante (final), na boca da betoneira estacionária de laboratório

\begin{tabular}{cc}
$\begin{array}{c}\text { Abatimento } \\
\text { inicial obtido } \\
(\mathrm{mm})\end{array}$ & $\begin{array}{c}\text { Abatimento } \\
\text { final obtido } \\
(\mathrm{mm})\end{array}$ \\
\hline 30 & 210 \\
\hline
\end{tabular}

Fonte: Autores, 2020

tos, aditivos e mão de obra. Na Tabela 5 , nota-se que todas as resistências especificadas no projeto estrutural foram atendidas durante o teste, com exceção da resistência na idade de 48h, que ficou aquém do limite mínimo de $20 \mathrm{MPa}$. No entanto, esse resultado não impossibilitou a aprovação e utilização desse traço, pois as resistências iniciais do concreto atenderam à capacidade de suporte desejada, conforme demonstrada nos itens seguintes.

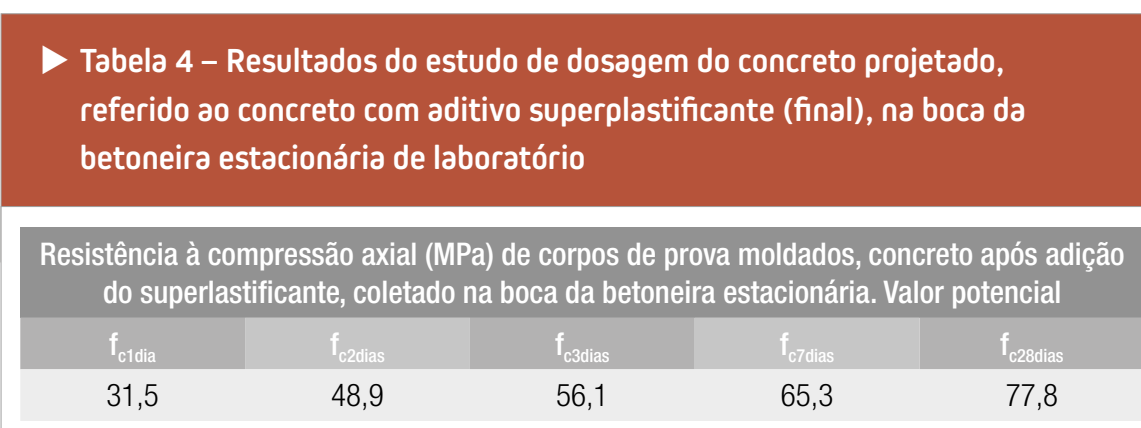

Tabela 5 - Resultados do teste tipo "protótipo" realizado em campo com

Resistência à compressão axial (MPa) de corpos de prova extraídos da placa de controle

\begin{tabular}{|c|c|c|c|c|c|}
\hline$f_{c 12 h}$ & $f_{c 24 h}$ & $f_{C 48 \mathrm{n}}$ & $f_{\text {cosilias }}$ & $f_{c 7 \text { dias }}$ & $f_{\text {cezodias }}$ \\
\hline 12,5 & 15,7 & 16,9 & 21,3 & 22,7 & 32,7 \\
\hline
\end{tabular}


Embora a obra possuísse outras empresas de serviços de concretagem homologadas, o fornecedor principal foi responsável por 3.878 viagens de caminhão betoneira num total de 3.961, representando $98 \%$ do fornecimento de concreto. Assim, foi considerado que, embora houvesse outras empresas de serviço de concretagem, este fator seja uma variável independente e constante.

\section{Z.Z E EUIPAMENTOS DE PROJEÇÃO}

Durante o experimento, foram utilizados dois tipos de equipamento de projeção, sendo uma bomba a rotor e outra bomba a pistão.

A escolha do tipo de equipamento deve-se às condições das frentes de serviço. Para distâncias menores, optou-se pela bomba a rotor. Já para vencer comprimentos de linha mais longos, a bomba a pistão mostrou-se mais conveniente.

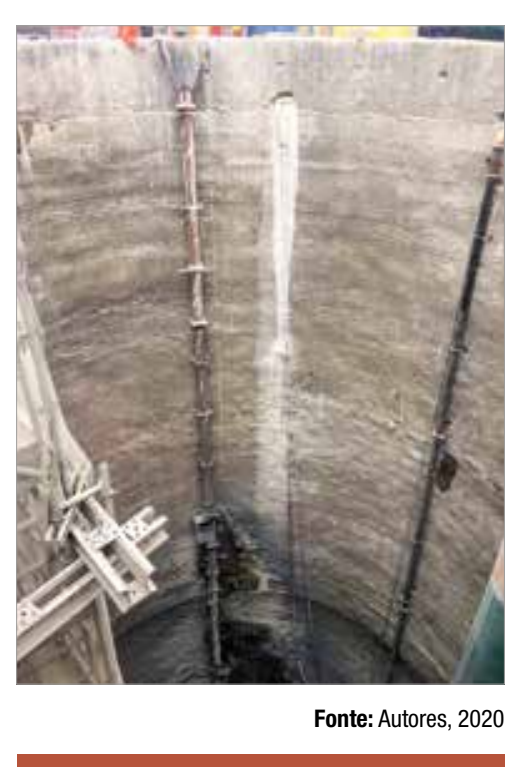

Figura 5

Tubulação para transporte vertical sem curvas ou dispositivos dissipadores de energia. Alternativa inadequada
O transporte vertical (para baixo, a partir da rua) do concreto também foi tema de bastante importância para a melhoria do processo, pois, em determinada frente de trabalho, foi constatado a segregação do material ao final da saída da tubulação junto à parede do poço (vide Fig. 5 e Fig. 6). A tubulação não contemplava curvas ou dispositivos atenuadores de energia, para diminuir a velocidade de queda do concreto, que tiveram de ser incorporados (vide Fig. 7).

\subsection{Fatores intervenientes}

Neste estudo, consideraram-se como fatores intervenientes aqueles que interferem consideravelmente nos valores dos resultados principais (variáveis dependentes). O fator principal, considerado no experimento em questão, foi o percentual de aditivo acelerador de pega no concreto.

$\mathrm{O}$ aditivo acelerador de pega tem efeito direto sobre a resistência do concreto, principalmente em baixas idades, onde o aditivo é responsável por tornar o concreto resistente, autoportante e capaz de fixar o maciço. Todavia, há um intervalo ideal de utilização, no qual o teor de aditivo seja suficiente para permitir o ganho de resistência em idades iniciais e não comprometer demais o desenvolvimento em idades finais (vide Fig. 8).

O intervalo de consumo recomendado pelo fabricante do aditivo utilizado situou-se entre 2\% e 8\%. Entretanto, o consumo está também associado à habilidade do operário mangoteiro, ao aparecimento de água na frente de escavação e ao próprio ângulo de projeção, que, no caso de calota (teto dos túneis), tende a consumir um teor mais elevado de acelerador, para garantir a

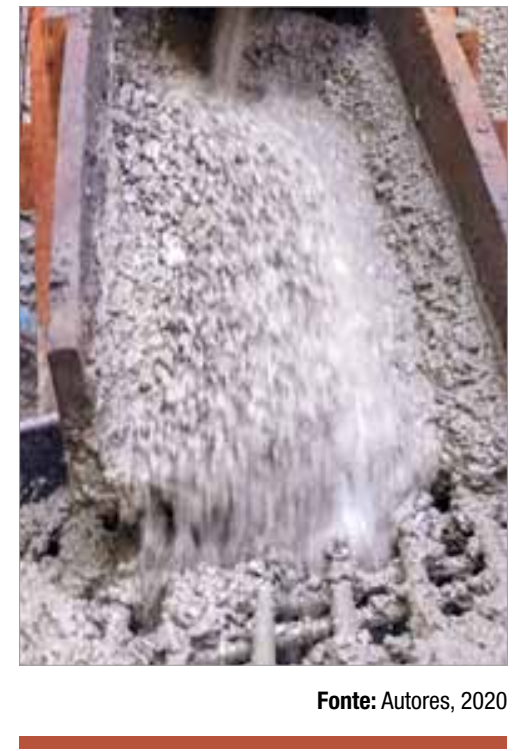

Figura 6

Tubulação inadequada. Ocorrência de concreto segregado na saída da tubulação

aderência do concreto no substrato projetado sobre cabeça.

Aspectos como consistência muito fluída, pressão de ar comprimido insuficiente ou fluxo intermitente na bomba tendem também a consumir mais aditivo acelerador, pois, na tentativa de corrigir esses fatores, o mangoteiro pode fazer uso indiscriminado do produto (vide Fig. 9).

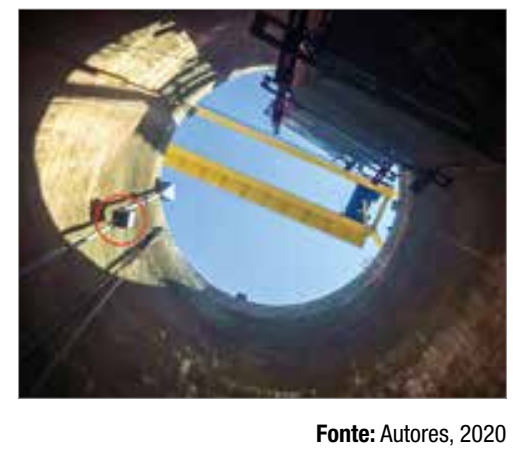

Figura 7

Inserção de caixas retentoras ao longo da tubulação para diminuir a velocidade de queda do concreto 


\section{RESULTADOS OBTIDOS}

\section{I Concreto fresco}

A avaliação do concreto fresco, através do abatimento inicial do tronco de cone (slump), é o primeiro requisito a ser atendido para o recebimento do concreto projetado na obra. Portanto, sua amostragem é total. Todos os caminhões recebidos durante o tempo do

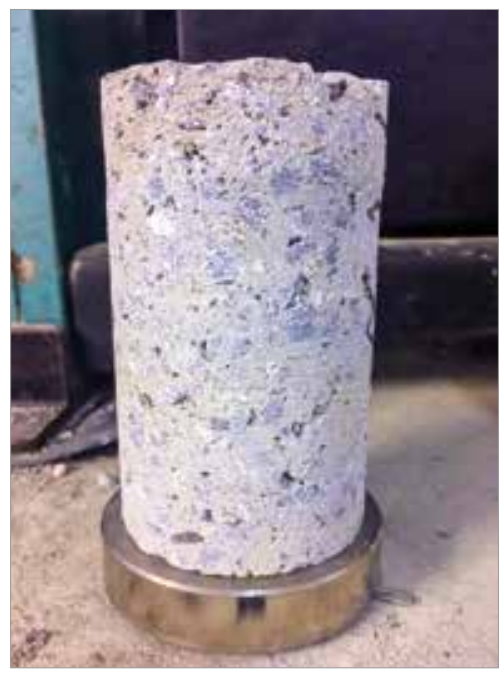

Fonte: Autores, 2020

Figura 8

Corpo de prova extraído de placa com aspecto característico

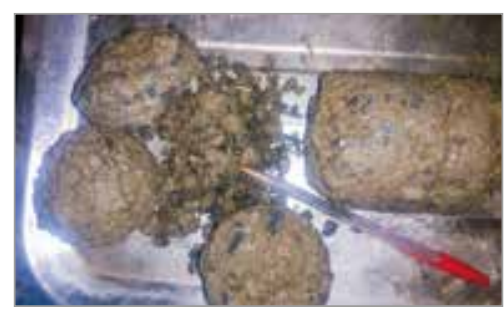

Fonte: Autores, 2020

Figura 9

Corpo de prova extraído de placa cujo concreto teve emprego excessivo de aditivo acelerador de pega. Observar material desagregando e frágil experimento tiveram seu slump inicial medido. No total, foram 3.961 viagens de caminhões betoneira.

Na Fig. 10 estão apresentados os valores do slump inicial. Ressalta-se que $95 \%$ dos valores enquadraram-se no intervalo de $(40 \pm 10) \mathrm{mm}$. Apenas $1,2 \%$ da amostragem ultrapassou 0 limite máximo estabelecido. Para esses casos, a regra foi devolver o concreto ao fornecedor. Nas situações onde o slump inicial encontrava-se abaixo do limite mínimo, porém dentro das tolerâncias da norma ABNT NBR 7212, foi permitido adicionar água e superplastificante e novamente aferido o slump.

A Fig. 11 apresenta os valores obtidos do slump final; $72,6 \%$ da população mostrou-se acima do limite máximo especificado no estudo do traço, que era de $210 \mathrm{~mm}$. A média do abatimento final foi de $220 \mathrm{~mm}$. Como essa consistência fluída foi obtida com aditivo, sem água extra, o concreto foi aceito e aplicado, porque não houve alteração da relação a/c máxima permitida.
A perda rápida de abatimento e a distância que o concreto percorria dentro da obra, da bica da betoneira até a frente de projeção, eram fatores que favoreciam aceitar a utilização de concretos mais fluídos, acima do especificado, desde que o concreto mantivesse seu aspecto homogêneo, sua capacidade de suporte do maciço, isento de segregação e com mesma relação a/c.

\subsection{Concreto jovem, até I20 minutos}

O Ensaio de Meynadier (Fig. 12) permite a observação da evolução da resistência do concreto projetado em idades baixas, possibilitando que o valor da resistência seja verificado sem a necessidade de interromper $\mathrm{o}$ andamento dos serviços.

É um ensaio não destrutivo e de obtenção imediata dos resultados. A amostragem recomendada por norma, para realização do ensaio, é um ensaio a cada $250 \mathrm{~m}^{2}$ de revestimento aplicado ou a cada 15 dias de produção,

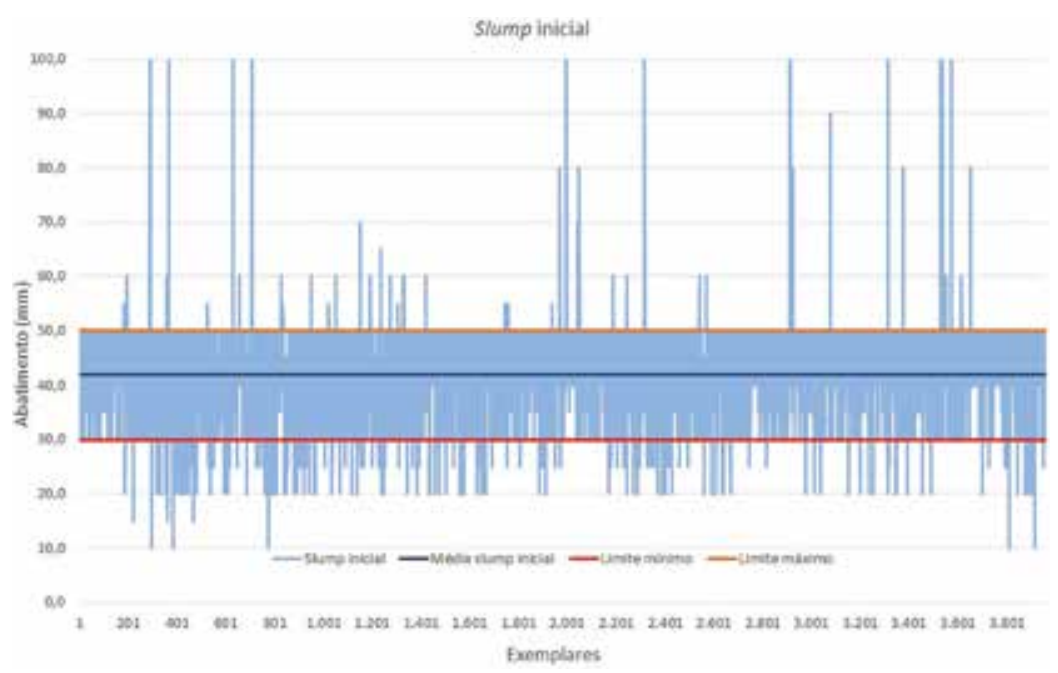

Fonte: Autores, 2020

Figura 10

Distribuição do abatimento inicial do concreto fresco aferido em cada BT 


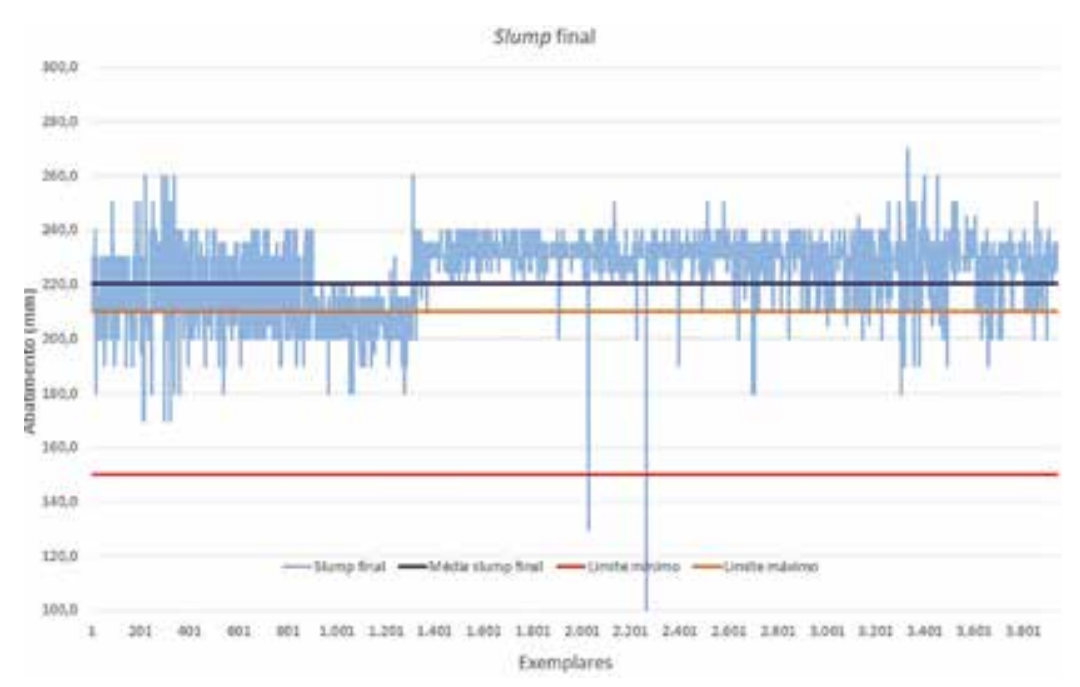

Fonte: Autores, 2020

Figura 11

Abatimento final do concreto fresco, após adição do aditivo superplastificante

empregando-se o Método A da EN 14488-2. No entanto, a obra foi mais rigorosa e adotou como amostragem um ensaio por dia em cada frente de serviço, o que possibilitou um universo amostral de mais de 800 ensaios, por idade, no concreto jovem, aumentando o conhecimento do processo.

Os ensaios foram realizados nas seguintes idades: 30 minutos, 60 minutos, 90 minutos e 120 minutos. Deve-se observar que o projeto estrutural não especificou valores mínimos em cada uma das idades citadas. Apesar dessa omissão, podem-se concluir dessa investigação alguns aspectos importantes.

Observou-se, por exemplo, que tentar medir resistência do concreto na idade de 30 minutos, após projeção
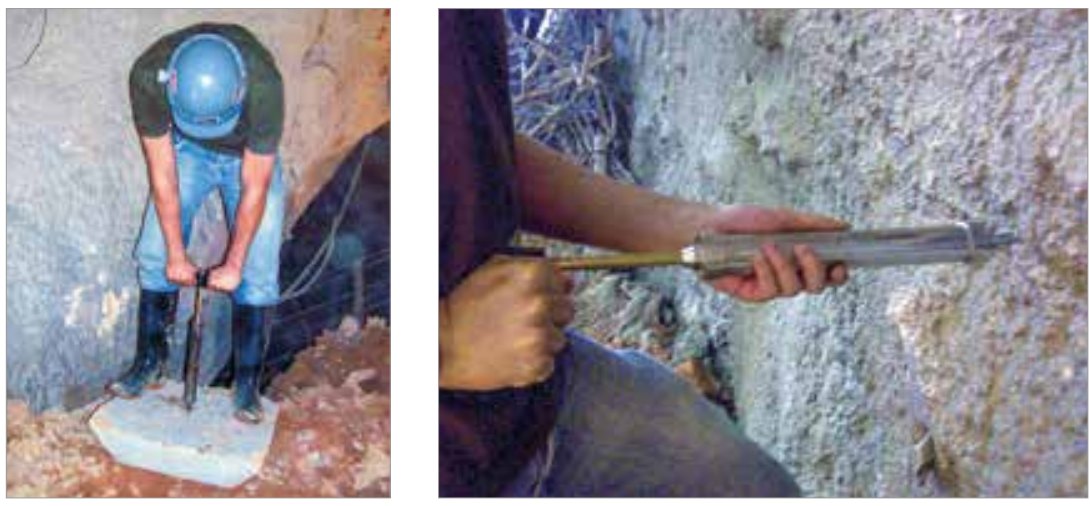

Fonte: Autores, 2020

\section{Figura 12}

Execução de ensaio com Agulha de Meynadier - na placa moldada para controle de resistência e na própria estrutura projetada na parede do túnel do concreto na parede do túnel, não se mostrou viável, pois muitas vezes a resistência foi tão baixa que impossibilitou obter medidas confiáveis da Agulha de Meynadier.

As medidas a 60 e 120 minutos mostraram-se mais confiáveis com menores variabilidades que a 30 minutos, porém os melhores resultados foram obtidos com ensaios a 90 minutos, ou seja, 1,5 h de idade. Por essa razão, optou-se por apresentar e discutir os resultados de 90 minutos.

Na Fig. 13 estão apresentados os valores das resistências à compressão do concreto com 90 minutos de idade, obtidos através do ensaio de Agulha de Meynadier.

No gráfico da Fig. 13, observam-se 812 ensaios realizados na idade de 90 minutos. Destaca-se que foi obtida uma resistência média geral de 0,68 $\mathrm{MPa}$, com valor característico, correspondente ao quantil inferior de $5 \%$, de 0,33 MPa, e desvio padrão da ordem de 0,21 MPa, ou seja, um coeficiente de variação ou variabilidade de $31 \%$.

Em princípio, 95\% do concreto aplicado atendeu a curva $\mathrm{J}_{1} / \mathrm{A}$ da Fig. 4, e consequentemente, $50 \%$ atendeu a curva de crescimento $\mathrm{J}_{2} / \mathrm{B}$, que em geral têm limites referidos aos valores médios de evolução das resistências a baixas idades.

Como a variabilidade foi de $31 \%$, considerada elevada, buscou-se entender a razão dessa heterogeneidade investigando uma correspondência entre resistência a baixa idade e teor de aditivo acelerador de pega, à base de sulfato de alumínio, líquido e isento de álcalis, adicionado no bico do mangote.

Então, além dos gráficos de resistências por idades, foram analisados os fatores intervenientes do processo. Assim, correlacionou-se as resistências ao 
percentual de aditivo acelerador utilizado durante a aplicação do concreto projetado.

Com relação ao consumo de aditivo acelerador, em todas as idades, observou-se comportamento similar. $\mathrm{O}$ intervalo entre $4 \%$ e $10 \%$ foi o de maior incidência (representando 84\% do total de resultados) (vide Fig. 14).

Ao analisar o percentual de consumo individualmente, conforme a Fig. 14 , observa-se que, no caso em questão, a partir de 6\% de teor de aditivo, as resistências do concreto jovem passaram a crescer sistematicamente, e a partir de $13 \%$ praticamente começaram a decair. Embora tenha sido observada essa tendência, que recomendaria utilizar teores acima de $6 \%$, a orientação em campo sempre foi considerar uma proporção entre $2 \%$ e $8 \%$, de acordo com o fabricante do produto.

Neste caso, na prática, nesses quase $20.000 \mathrm{~m}^{3}$, os teores efetivos de aditivo acelerador de pega, à base de sulfato de alumínio, variaram bastante e não seguiram exatamente o recomendado pelo fabricante, conforme se pode observar no gráfico da Fig. 15.

Destaca-se que adições superiores ao recomendado pelo fabricante, que ocorrem por conta de ajustes do mangoteiro já explicadas anteriormente, podem acarretar reduções indesejáveis na resistência final do concreto, aos 28 dias de idade, como se apresenta a seguir.

\subsection{Concreto endurecido, resistência até 28 dias de idade}

Para a análise do concreto endurecido, foram realizados ensaios de resistência à compressão de corpos de prova (testemunhos), extraídos de placas moldadas durante a aplicação

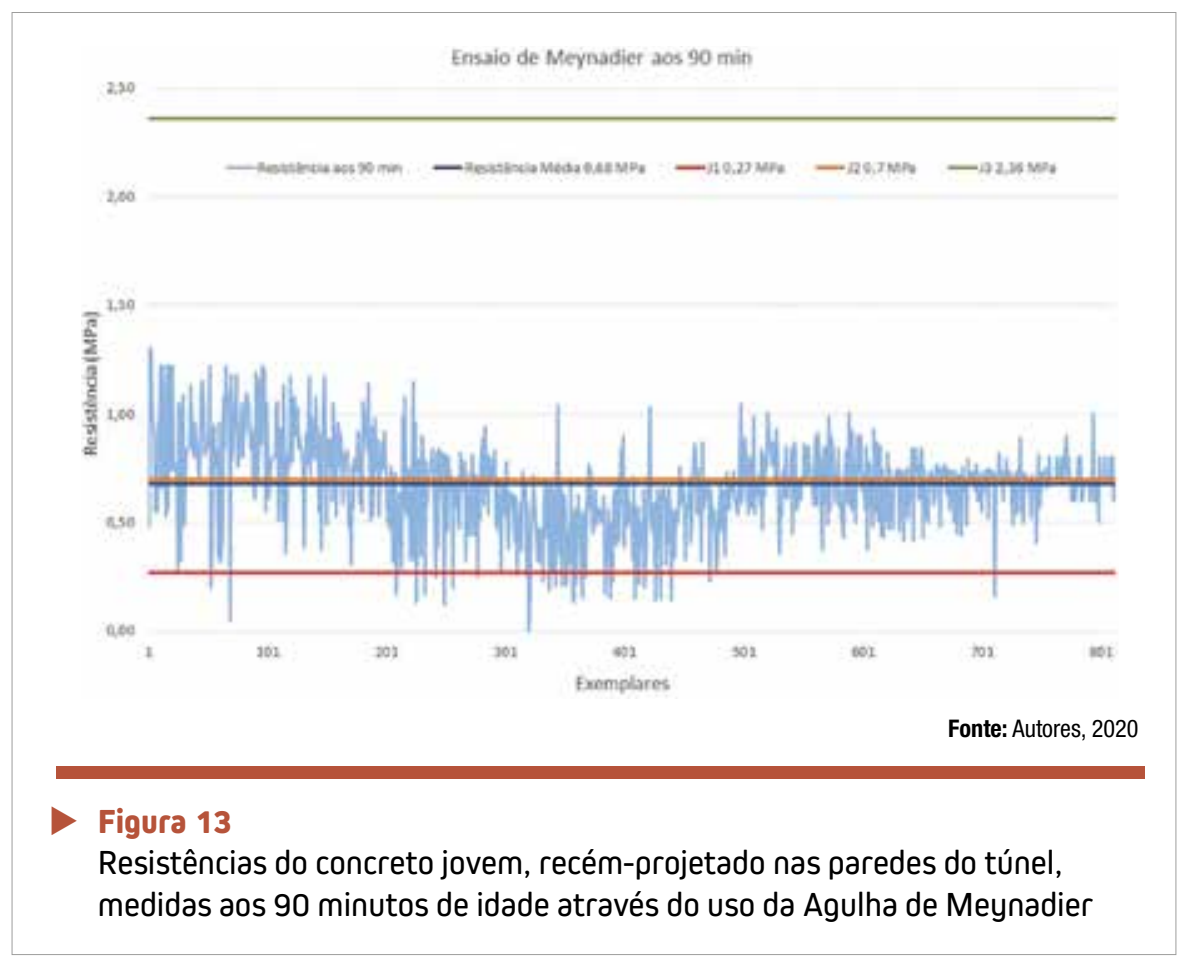

do concreto, nas idades de $12 \mathrm{~h}, 24 \mathrm{~h}$, 48h, 3 dias, 7 dias e 28 dias. Ressalta-se que o projeto não especificava as idades de 3 dias e 7 dias.

A frequência mínima recomendada para os ensaios, era um a cada 3 dias ou $80 \mathrm{~m}^{3}$ de produção. Todavia, a obra foi mais rigorosa e adotou como premissa a mesma sistemática de ensaios apresentada para o concreto jovem, ou seja, um ensaio por dia por frente de serviço. No caso do concreto endurecido, foi possível obter um universo

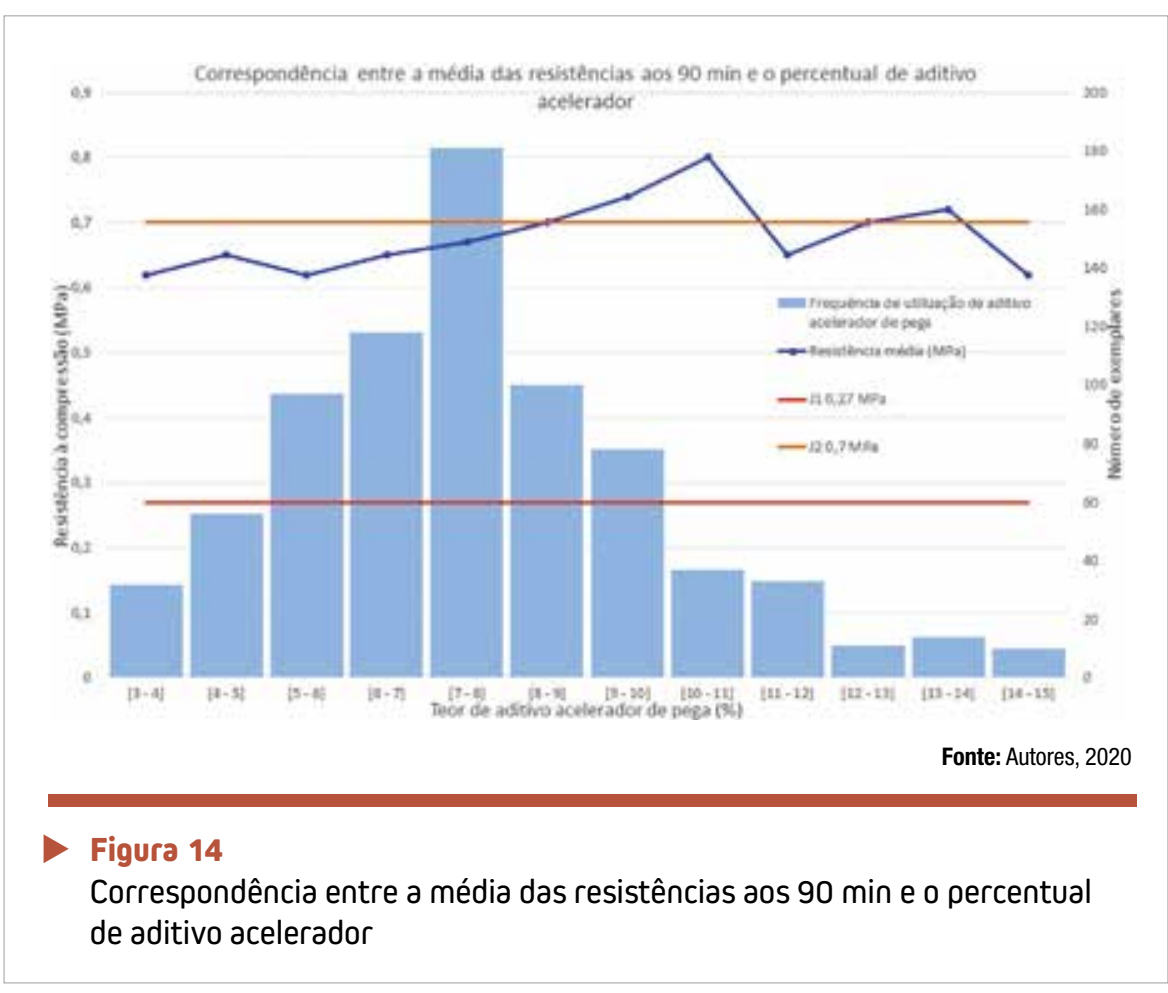




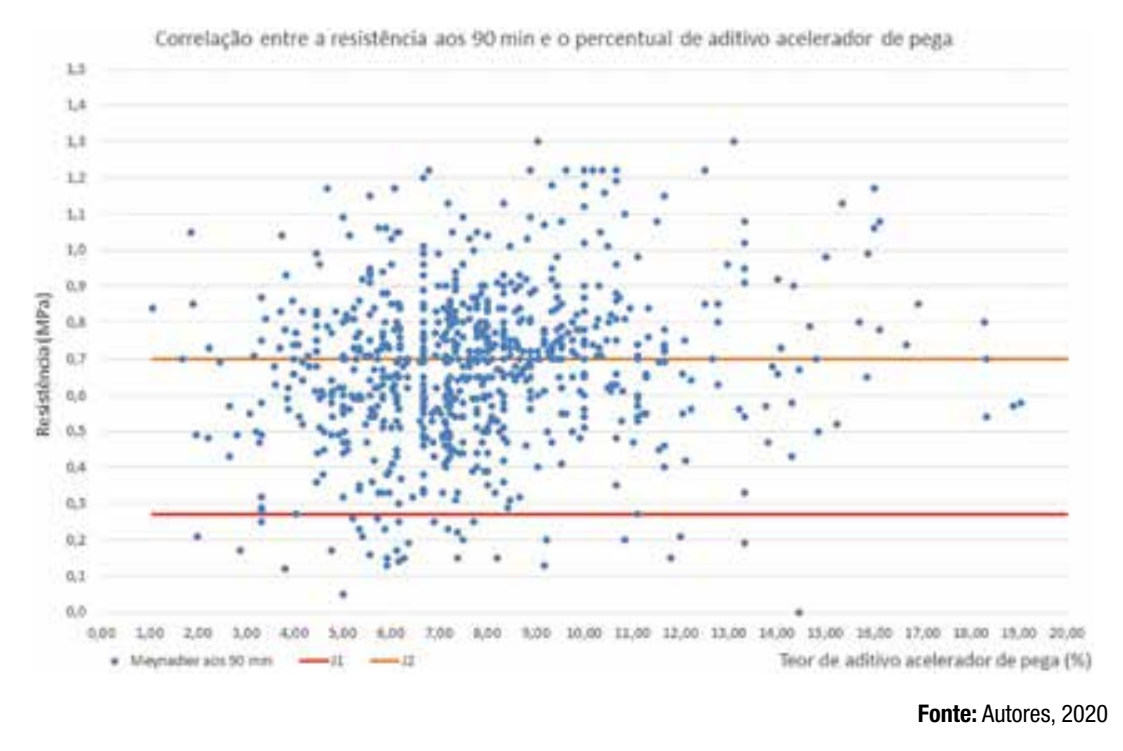

Figura 15

Correspondência entre a resistência aos 90 min, em MPa, e o percentual de aditivo acelerador de pega, em \% em massa de cimento

amostral superior ao do concreto

1. Às $12 \mathrm{~h}$ de idade, observou-se $66 \%$ jovem. Foram analisados mais de 1.300 ensaios na idade de $24 \mathrm{~h}$ e mais de 1.500 aos 28 dias de idade (vide Fig. 16 e Fig. 17).

Os resultados mostraram que: dos resultados acima do especificado em projeto (10 MPa), com média de 11,9 MPa, ou seja, atendeu plenamente a especificação com referência à resistência média;

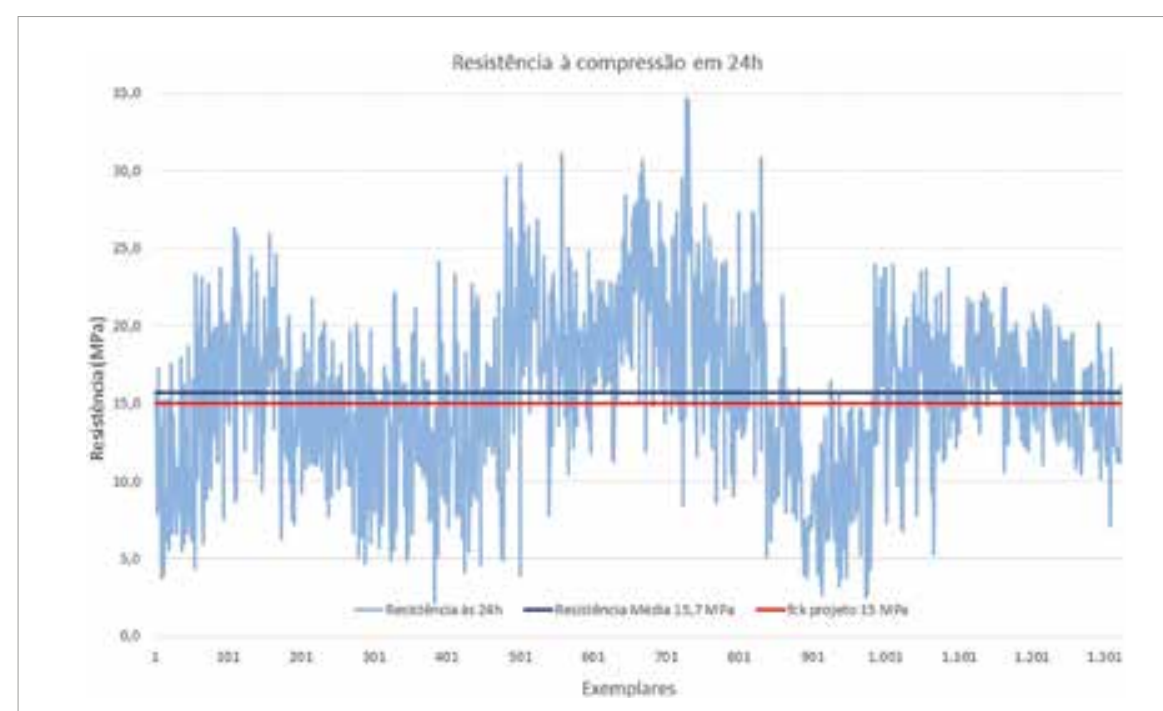

Fonte: Autores, 2020

\section{Figura 16}

Resistência à compressão em 24h, considerado um período total de 20 meses de obra
2. Às $24 \mathrm{~h}$ de idade, observou-se $56 \%$ dos resultados acima do especificado em projeto (15 MPa), com média de 15,7 MPa, ou seja, atendeu plenamente a especificação com referência à resistência média;

3. Às $48 \mathrm{~h}$ de idade, observou-se $45,8 \%$ de resultados acima de 20 MPa, com média de 19,4 MPa, ou seja, não atendeu plenamente a especificação com referência à resistência média;

4. Aos 3 dias, média de 23,1 MPa;

5. Aos 7 dias, média de 27,7 MPa;

6. Aos 28 dias, a média geral superou, com folga, o valor especificado no projeto de $\mathrm{f}_{\mathrm{cj}}=30 \mathrm{MPa}$, com média efetiva de 33,3 MPa;

7. Aos 28 dias de idade, a resistência característica do concreto à compressão, foi de 22,1 MPa, e não atendeu o valor especificado de $25 \mathrm{MPa}$, ou seja, 95\% do volume total de concreto superou 22,1 MPa, quando deveria ter superado $25 \mathrm{MPa}$;

8. $\mathrm{Na}$ realidade, aos 28 dias de idade, $10 \%$ do volume de concreto apresentou-se com resistência abaixo de $25 \mathrm{MPa}$, ou seja, somente $90 \%$ do concreto aplicado superou a resistência característica de $25 \mathrm{MPa}$, quando, no Brasil, segundo a ABNT NBR 12655, deveriam ser 95\% do volume de concreto acima de $25 \mathrm{MPa}$. Mas se considerado o valor característico especificado na norma americana $\mathrm{ACl}$ 318 , denominado $f_{c^{\prime}}$, estaria conforme, pois nessa norma o quantil superior é exatamente 90\%.

Assim como no concreto jovem, também foram analisadas as variáveis que interferem no ganho de resistência. A distribuição dos dados, 
ao longo das idades do concreto endurecido, é semelhante (vide Fig. 19).

No gráfico da Fig. 19, aos 28 dias de idade, não foi possível constatar qualquer relação entre a média das resistências e os teores de aditivo acelerador de pega, ou seja, o teor de aditivo não interferiu na resistência aos 28 dias do concreto quanto à sua variabilidade, apesar de haver interferido significativamente na redução da resistência média aos 28 dias.

O gráfico da Fig. 20 apresenta a comparação entre as resistências obtidas de testemunhos das placas de controle do concreto projetado e as resistências potenciais do concreto, na bica da betoneira, obtidas de corpos de prova moldados após adição do aditivo superplastificante, porém sem aditivo acelerador de pega.

Aos 28 dias (Fig. 20), observa-se que as resistências sem o aditivo acelerador resultaram em média $26 \%$ superiores às obtidas das placas de controle. Foram analisadas 1.194 amostras. A resistência média das amostras coletadas diretamente da bica da betoneira, ou seja, sem o aditivo acelerador, é igual a 44,8 MPa. Destaca-se que a resistência encontrada em laboratório para a mesma idade (28 dias) foi de 77,8 MPa, deste modo, a resistência média das amostras sem o aditivo acelerador foi $42 \%$ menor do que esse valor inicial de laboratório, e a resistência média das amostras com aditivo acelerador, 57\% menor, o que reforça a importância de estudos prévios tipo "protótipo", pois há grande influência negativa do processo de produção no resultado final da resistência. Parte desse efeito negativo é devida ao aditivo acelerador e parte ao processo propriamente dito

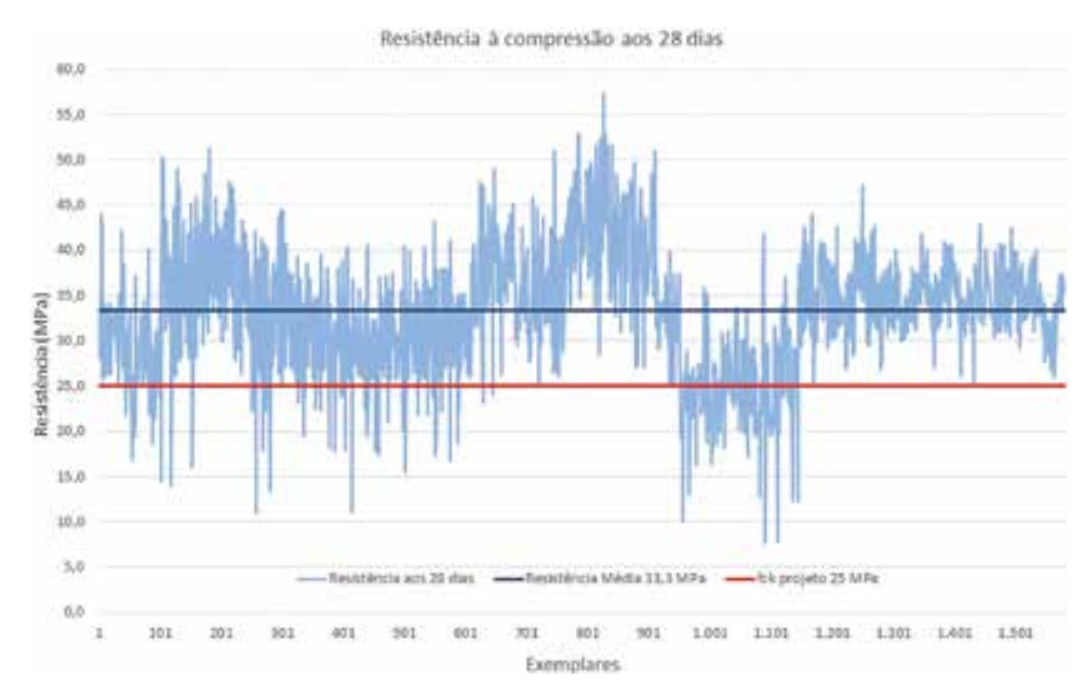

Fonte: Autores, 2020

Figura 17

Resistência à compressão aos 28 dias, considerado um período total de 20 meses de obra

como um todo, incluindo os efeitos nefastos de broqueamento (extração).

Ainda no gráfico da Fig. 20, torna-se notório o impacto do aditivo acelerador de pega na redução das resistências do concreto endureci- do. Enquanto a utilização do aditivo é fundamental para que o concreto ganhe resistência inicial e se torne autoportante em baixas idades, ele acarreta uma redução das resistências em idades mais avançadas.

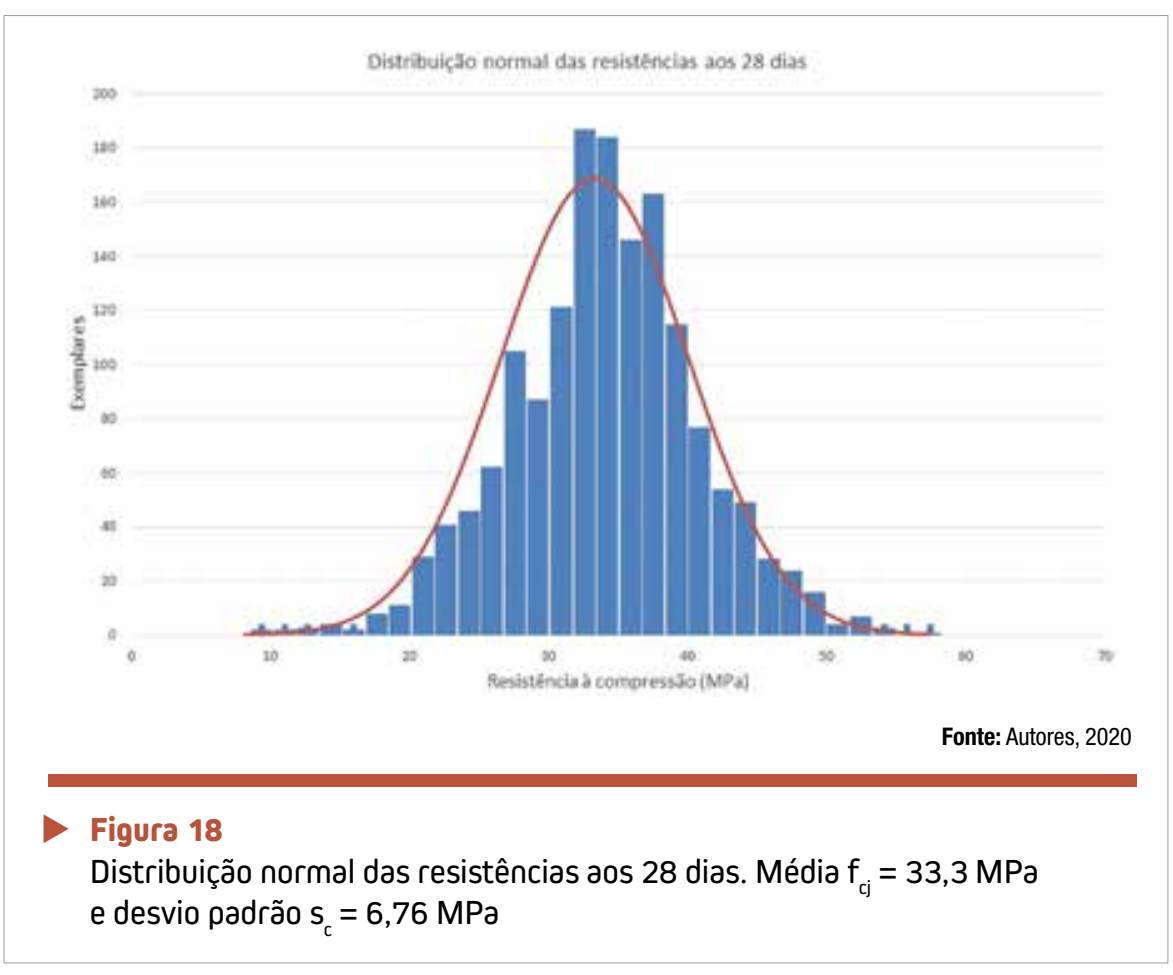




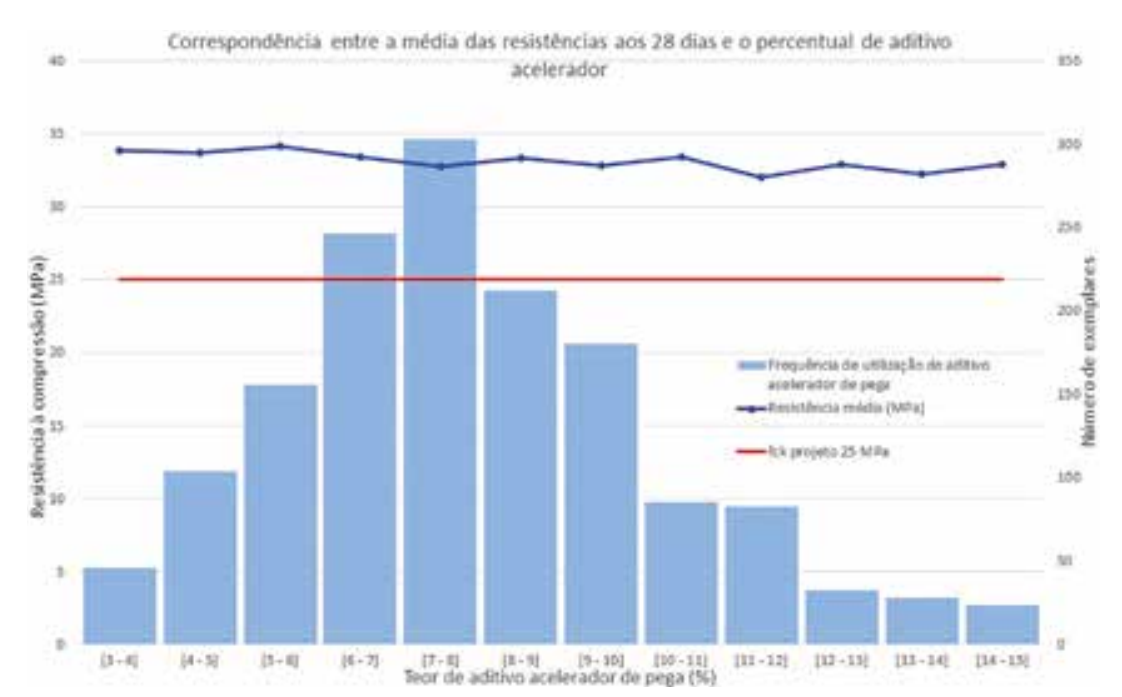

Fonte: Autores, 2020

Figura 19

Correspondência entre a média das resistências aos 28 dias e o percentual de aditivo acelerador

\section{CONCLUSÕES}

A partir dos resultados, é possível inferir que, no concreto jovem, o ganho de resistência é mais evidenciado com o consumo de aditi- vo acelerador no intervalo de $6 \%$ a $10 \%$ de utilização do produto. E que o mesmo comportamento não se repetiu no concreto endurecido, ou seja, aos 28 dias, as médias das re-

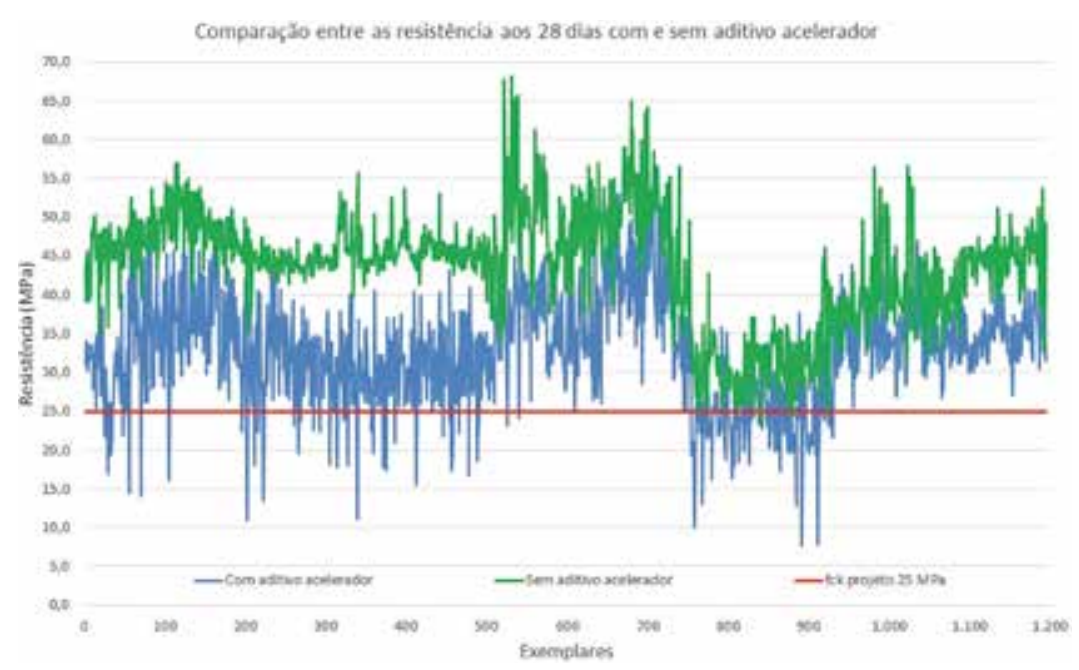

Fonte: Autores, 2020

Figura 20

Comparação entre as resistências aos 28 dias do concreto da bica do caminhão (sem acelerador) e dos corpos de prova extraídos das placas de controle (pós acelerador) sistências, por faixa de consumo de aditivo, mantiveram-se praticamente inalteradas.

Embora o intervalo do consumo percentual de aditivo, no qual as resistências iniciais tenham se mostrado mais elevadas, seja entre 6\% e 10\%, é necessário avaliar também os custos envolvidos, pois um maior consumo implica maior gasto com material. Portanto, é importante gerenciar as condições de aplicação do concreto, pois pode-se controlar a vazão para um desempenho mais eficaz, tanto do ponto de vista de qualidade quanto econômico.

Destaca-se, ainda, a grande representatividade deste estudo, pois o universo amostral apresentado neste trabalho foi superior ao recomendado pelas normas. Para ensaios de resistência em baixa idade, por exemplo, deve ser realizada uma determinação a cada $250 \mathrm{~m}^{2}$ de revestimento ou a cada 15 dias de produção, o que resultaria a menos de um terço dos resultados totais obtidos.

Considerando que um ciclo médio de escavação tem duração normal de $6 \mathrm{~h}$, os ensaios realizados neste período são os de maior relevância para a segurança e continuidade das atividades. Desta forma, é evidente que a realização dos ensaios nas primeiras horas não pode ser negligenciada. E, por conseguinte, a revisão da frequência de ensaios, principalmente no concreto jovem, pode ser considerada como ponto de melhoria do processo.

Neste experimento, observou-se que o maior volume de ensaios realizados foi no concreto endurecido, ou seja, após $12 \mathrm{~h}$ do final de um ciclo de escavação. Os ensaios realizados no concreto endurecido 
são destrutivos. O processo desses ensaios envolve a coleta e transporte das placas moldadas das frentes de serviço ao Laboratório, extrações das amostras, preparação, armazenamento e ruptura dos corpos de prova. Ao final do processo, ainda há um problema ambiental, com grande geração de resíduos e necessidade de destinação adequada. Logo, além desses ensaios serem onerosos para o empreendimento, já que envolvem mão de obra especializada, equipamentos específicos, custos com destinação de resíduos, eles não refletem a real prioridade de se obterem resultados imediatos em prol da segurança dos túneis.

Mais úteis foram as resistências aferidas no concreto jovem. Observa-se que as resistências iniciais, fundamentais à segurança dos operários e necessárias ao suporte do maciço, foram plenamente atendidas e o ensaio com Agulha de Meynadier mostrou-se muito efetivo. Aos 28 dias de ida- de, no entanto, o $f_{c k, e s t}$, segundo a ABNT NBR 12655 não atendeu ao projeto de $\mathrm{f}_{\mathrm{ck}}=25 \mathrm{MPa}$. Todavia, se considerado à luz da norma americana $\mathrm{ACl} 318$, houve conformidade.

Por fim, salienta-se a importância da avaliação rigorosa do fornecimento do concreto. É fundamental que o traço esteja de acordo com o especificado, pois qualquer alteração de seus componentes, principalmente do consumo de cimento, incorre na alteração significativa das propriedades do concreto fresco e endurecido.

Como observado no experimento, o concreto projetado, sem a utilização de aditivo acelerador, ou seja, obtido diretamente da bica da betoneira, apresenta um resultado mais de $25 \%$ superior à resistência do testemunho retirado da placa que contém o aditivo acelerador. Entretanto, esse mesmo concreto, coletado da bica da betoneira, durante o processo, apresenta uma resistência média à compressão da ordem de 0,6 da resistência alcançada no laboratório, no momento do estudo experimental de dosagem.

Essa diferença é excessiva e denota a complexidade e descontrole do processo de produção, que requer melhoramentos. Cabe ressaltar, ainda, que uma eventual redução indevida da massa de cimento no traço, sem que se façam os ajustes necessários do teor de aditivo acelerador, incide em um consumo excessivo do aditivo, que irá impactar no custo e no risco à saúde dos operários, engenheiros e pessoal das frentes de trabalho.

\section{AGRADECIMENTOS}

A autora agradece aos profissionais de campo (Auxiliares de Laboratório, Técnicos da Qualidade, Operadores de bomba, Mangoteiros e seus Auxiliares), sem os quais, este estudo não seria factível. Agradece também aos Professores do Curso de Mestrado Profissional do IPT pelos conhecimentos adquiridos.

\section{DREFERÊNCIAS BIBLIOGRÁFICAS}

[01] AMERICAN CONCRETE INSTITUTE. ACI 318-19: Building Code Requirements for Structural Concrete and Commentary. Farmington Hills, 2019.

[02] ARMELIN, Hugo Soaygar. Contribuição ao Estudo do Concreto Projetado por Via Seca com fibras de Aço Destinado ao Revestimento de túneis NATM. São Paulo, 1992. Dissertação de Mestrado. Escola Politécnica da Universidade de São Paulo.

[03] ASSOCIAÇÃO BRASILEIRA DE NORMAS TÉCNICAS. NBR 5739: Concreto - Ensaio de compressão de corpos de prova cilíndricos. Rio de Janeiro, 2018.

[04] ASSOCIAÇÃO BRASILEIRA DE NORMAS TÉCNICAS. NBR 7212: Execução de concreto dosado em central — Procedimento. Rio de Janeiro, 2012.

[05] ASSOCIAÇÃO BRASILEIRA DE NORMAS TÉCNICAS. NBR 7680-1: Concreto - Extração, preparo, ensaio e análise de testemunhos de estruturas de concreto - Parte 1: Resistência à compressão axial. Rio de Janeiro, 2015.

[05] ASSOCIAÇÃO BRASILEIRA DE NORMAS TÉCNICAS. NBR 12655: Concreto de cimento Portland - Preparo, controle, recebimento e aceitação - Procedimento. Rio de Janeiro, 2015.

[06] ASSOCIAÇÃO BRASILEIRA DE NORMAS TÉCNICAS. NBR NM 67: Concreto - Determinação da consistência pelo abatimento do tronco de cone. Rio de Janeiro, 1998.

[07] EFNARC. European specification for sprayed concrete, 1996. Disponivel em: <http://www.efnarc.org/pdf/EuroConcreteSpecEng.pdf>. Acesso em: 09 abr. 2019.

[08] EUROPEAN STANDARDS. BS EN 14488-2: Testing sprayed concrete Compressive strength of young sprayed concrete. 2006.

[10] FIGUEIRED0, Antonio Domingues de. Parâmetros de Controle e Dosagem do Concreto Projetado com Fibras de Aço. São Paulo, 1997. Tese de Doutorado. Escola Politécnica da Universidade de São Paulo.

[11] PALERMO, Giovanni. Concreto Projetado como Revestimento de Túneis. São Paulo, 1997. Dissertação de Mestrado. Escola Politécnica da Universidade de São Paulo.

[12] PRUDÊNCIO Jr, Luis Roberto. Contribuição à Dosagem do Concreto Projetado. São Paulo, 1993. Tese de Doutorado. Escola Politécnica da Universidade de São Paulo.

[13] SILVA, Paulo Fernando A.. Concreto projetado para túneis. São Paulo: Pini, 1997. 92 p. 